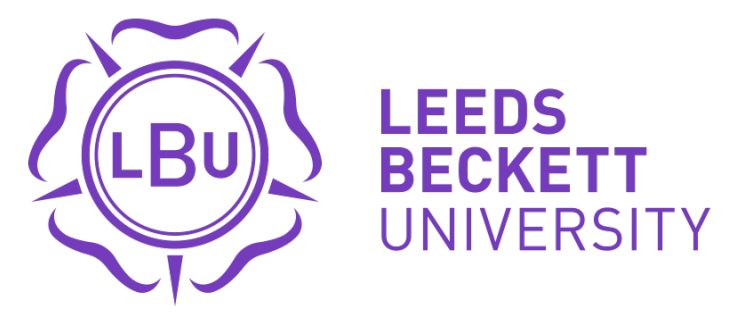

Citation:

Gardiner, $\mathrm{C}$ and El-Sherbini, N and Perry, S and Alderdice, $\mathrm{J}$ and Harman, A and Tarm, L (2019) The Renal Dietetic Outcome Tool (RDOT) in clinical practice. Journal of Kidney Care, 4 (3). pp. 116-124. ISSN 2397-9534 DOI: https://doi.org/10.12968/jokc.2019.4.3.116

Link to Leeds Beckett Repository record:

https://eprints.leedsbeckett.ac.uk/id/eprint/6227/

Document Version:

Article (Accepted Version)

This is the Accepted Version of the following article: The Renal Dietetic Outcome Tool (RDOT) in clinical practice, Claire Gardiner, Nevine El-Sherbini, Sue Perry, Jane Alderdice, Annabel Harman, and Linda Tarm, Journal of Kidney Care 2019 4:3, 116-124, which has been published in final form as 10.12968/jokc.2019.4.3.116. This article may be used for non-commercial purposes in accordance with the MA Healthcare Self-Archiving Policy.

The aim of the Leeds Beckett Repository is to provide open access to our research, as required by funder policies and permitted by publishers and copyright law.

The Leeds Beckett repository holds a wide range of publications, each of which has been checked for copyright and the relevant embargo period has been applied by the Research Services team.

We operate on a standard take-down policy. If you are the author or publisher of an output and you would like it removed from the repository, please contact us and we will investigate on a case-by-case basis.

Each thesis in the repository has been cleared where necessary by the author for third party copyright. If you would like a thesis to be removed from the repository or believe there is an issue with copyright, please contact us on openaccess@leedsbeckett.ac.uk and we will investigate on a case-by-case basis. 


\title{
The Renal Dietetic Outcome Tool (RDOT) in clinical practice
}

\author{
C Gardiner ${ }^{1}$ N El-Sherbini², S Perry ${ }^{3}$ J Alderdice ${ }^{4}$, A Harman ${ }^{5}$, L Tarm ${ }^{6}$ \\ ${ }^{1}$ Leeds Teaching Hospitals Trust, Leeds \\ ${ }^{2}$ Imperial College Healthcare NHS Trust, London \\ ${ }^{3}$ Hull and East Yorkshire Hospitals NHS Trust, Hull \\ ${ }^{4}$ Manchester University NHS Foundation Trust, Manchester \\ ${ }^{5}$ Epsom and St Helier University Hospitals NHS Trust, Epsom \\ 'Guy's \& St Thomas' NHS Foundation Trust, London
}

Corresponding author: Claire gardiner, c.gardiner@leedsbeckett.ac.uk, 0113

\section{3}

\section{$\underline{\text { Abstract }}$ \\ Background}

The Renal Nutrition Group of the British Dietetic Association (BDA-RNG) developed three renalspecific Dietetic Outcome Models and a Renal Dietetic Outcome Tool (RDOT) to measure dietetic outcomes in potassium and phosphate management and oral nutrition support in patients with Chronic Kidney Disease (CKD).

Methods

Participating renal units collected relevant outcome data using the RDOT for all newly referred outpatients with CKD stage 4 or 5 within a three month period excluding patients with a functioning kidney transplant.

Findings 
21 units collectively completed data on 742 patients. $87 \%$ achieved their outcome for potassium management, $66 \%$ for phosphate management and $58 \%$ for oral nutrition support (ONS). Patients seen two or more times by the renal dietitian demonstrated improved outcomes particularly those on haemodialysis $(p=0.01)$.

\section{Conclusion}

The RDOT can be used to evaluate current renal dietetic services to assist with development of service provision and workforce planning as well as to compare renal dietetic services across the UK.

\section{$\underline{\text { Introduction }}$}

Providers and commissioners of care require both cost and clinically effective services within the National Health Service (NHS). However, this is challenging for all disciplines within the multiprofessional team due to limited resources and increased demands, leading to lack of time for quality measurement.

Since 2010 there have been three key publications directing dietitians to the importance of measuring clinical outcomes (DOH 2010, BDA 2011, HCPC 2013). In addition, the NHS Five-Year Forward View for England (NHS England 2014) outlines an on-going drive for improving the quality of care using the three main themes of patient experience, safety and effectiveness. In clinical practice, healthcare utilisation and cost outcomes as well as mortality and morbidity rates are often used to measure the impact of interventions (DOH 2016). As there are many healthcare professionals that contribute to the patient's care plan to achieve these outcomes, the parameters used to show effectiveness can lead to blurred lines of accountability between medical, pharmacology, dietetic and nursing interventions. Enhanced understanding of the outcomes relating to dietetic interventions would lead to strengthening the value of evaluating and improving dietetic services provided. 
In the UK, Allied Health Professionals use a variety of therapy tools, models and systems to determine the impact of their intervention, relating to their service type and client groups. Dietitians in the UK have utilised a variety of models including Therapy Outcome Measures (Enderby et al. 2015) and the Care aims approach (Malcomess and Wilson 2015). However, none of the therapy models have proved generally applicable, amenable, or transferable to the work of dietitians in the acute care setting where the emphasis is on nutritional status and nutritional intake.

The identification and development of outcome measures for dietetics has been an on-going challenge for the profession. It is only in recent years that dietitians have started to develop and share tool kits for measuring dietetic outcomes in patients requiring nutrition support (Davies 2016; PENG 2016).

Where there is research into the impact of renal dietetic intervention on patient outcomes, it is often limited and low grade (Ash et al. 2014). Outcomes tend to focus on one biochemical endpoint (Sullivan et al. 2009; Reddy et al. 2009; Karavetian and Ghaddar 2013) or a measure of nutritional status (Stratton et al. 2005; Bellizzi et al. 2010). The studies fail to capture the context of the clinical setting, what facilitates or hinders change and how this impacts on patients' outcome and experience. Only a few studies have shown the effectiveness of dietary intervention in practice (Campbell et al. 2009; Calderia et al. 2011).

In 2011 a working group of the BDA-RNG was formed to develop guidance on identifying and capturing dietetic outcomes for renal dietitians in clinical practice. Prior to starting this work, there were no UK validated, sensitive and reliable, dietetic outcome measures available for routine use in clinical practice (BDA 2011). Steiber et al (2015) has since developed a nutrition algorithm which is a computerised aid to help clinical decisions as well as track dietetic outcomes in haemodialysis patients. 
The RNG Dietetic Outcomes Pack developed by the working group can be accessed on (https://www.bda.uk.com/regionsgroups/groups/renal/outcometools) and consists of:

- Three outcome models on potassium and phosphate management and ONS Although in clinical practice the renal dietitian may advise on a combination of dietary issues during one consultation, it was felt that collecting data relating to individual dietetic interventions would provide greater understanding of the impact of a dietetic intervention in CKD. Each model outlines the main outcome, timeframe and rationale of the intervention as well as a list of SMART goals to be identified and agreed with the patient at the start of the episode of care. Various markers and tools to measure changes in goals are suggested.

- A list of barriers - identification of barriers may increase understanding of why goals and outcomes are not achieved

- A list of interventions - these may be implemented to address the barriers and help improve the patients experience and outcomes

- The RDOT - this captures all the relevant information above.

Further details of the RNG Outcomes Pack is discussed in the article by Gardiner, Harman and Alderdice (2015).

In order to fully assess the functionality of the RDOT, funding was obtained from the BDA to undertake a multicentre audit. The primary aim of this multicentre audit was to determine if the use of the RDOT could capture changes in parameters used to measure nutritional status and biochemical measures in outpatients receiving dietetic intervention in clinical practice. The secondary aim was to ascertain the impact of potential barriers and facilitators on the success of the patient outcome.

\section{Methods}


119 renal dietetic units, attached to UK NHS hospitals, were eligible to take part in the audit.

Recruitment of units was conducted via invitation through emailing BDA-RNG group members via a members discussion forum as well as disseminating details at national meetings and in national journals. A letter clarifying the purpose, safety and security of the audit data was made available to share with the participating trusts Research and Audit department. No ethical approval was required as the audit only required outcome data from routine dietetic practice and did not involve collecting demographics or personal data.

Participating units were provided with the RNG Dietetic Outcomes Pack, the RDOT (on an Excel spreadsheet), an audio-visual guide of 'How to Complete the Tool' and a Frequently Asked Questions' document. A mentor from the BDA-RNG working group was allocated to each unit to provide any support and guidance needed. The audit was conducted from September 2013 to May 2014.

Each unit was instructed to collect relevant outcomes data from all eligible outpatients referred in the first three months of the audit, inputting data into the RDOT. Inclusion and exclusion criteria were provided (Table 1). No minimum or maximum numbers of patients were imposed.

\section{Table 1: Patient inclusion and exclusion criteria}

\begin{tabular}{|l|l|}
\hline Inclusion Criteria & Exclusion criteria \\
\hline $\begin{array}{l}\text { Male and female adult patients ( } \geq 18 \text { years old) with CKD } \\
\text { stage } 4 \text { and } 5 .\end{array}$ & Inpatients \\
$\begin{array}{l}\text { All new outpatient referrals for dietary management of } \\
\text { serum potassium or phosphate, or oral nutrition } \\
\text { support }\end{array}$ & Paediatric patients \\
\hline
\end{tabular}

Dietitians were instructed to focus on collecting outcomes data on one dietary intervention at a time, i.e. potassium, phosphate or ONS. When the patient was provided with more than one dietary intervention, data was collected as individual entries or the main intervention was prioritised for data collection. 
At the start of the episode of care, collection of data included patients' modality, date of first assessment, goals set, barriers at start of episode of care and the overall outcome being measured e.g. serum phosphate. A drop down menu provided options for most of the data entry.

At the end of the episode of care, data was recorded to include date of final review, the outcome measured e.g. serum phosphate, number of reviews undertaken and outcome of each goal set (categorised as not achieved, progress towards, achieved, and achieved and maintained). The outcome of each goal was determined by outcome measures as suggested in the outcome models. Barriers at the end of episode of care, use of interventions and the result of the overall clinical outcome were also recorded.

The timeframe allowed any number of reviews within a maximum of six months from the initial assessment to allow sufficient time for the episode of care to be completed. The length of episode of care was automatically calculated in the RDOT.

A positive outcome was defined as the overall desired outcome being met e.g. "to achieve and maintain a serum phosphate within the target range".

Upon completion of the audit, all units emailed their completed RDOT to their allocated mentor for analysis using secure email. All results were presented as n (\%); mean and SD were calculated using Excel. Wilcoxon test was used to determine the difference in measurements (serum potassium, phosphate, weight) from start to end of episode of care and in relation to number of times seen using a statistical program R core team (2015); where statistical significance was agreed at $p<0.05$.

\section{$\underline{\text { Results }}$}

A convenience sample of $27 / 119$ (22\%) renal dietetic units agreed to participate in the audit. $78 \%$ ( $n=21 / 27$ ) completed the audit, submitting the completed RDOT at the end of the nine months. 
Five did not start the audit due to staffing issues and one unit completed the tool incorrectly and the data could not be used. Thirty three entries into the RDOT where the final outcome was not recorded were removed from the analyses. Complete data was collected on 742 episodes of care with $32 \%$ ( $n=235 / 742)$ for potassium management, $50 \%(n=369 / 742)$ for phosphate management and $18 \%(n=138 / 742)$ for ONS. Table 2 shows the CKD stage and the number of consultations.

\section{Table 2: Characteristics}

$\mathrm{HD}=$ Haemodialysis $\mathrm{PD}=$ Peritoneal dialysis $\mathrm{CM}=$ Conservative management; $\mathrm{MD}=\mathrm{Missing}$ data

\begin{tabular}{|c|c|c|c|c|c|c|c|c|c|c|c|c|c|c|c|}
\hline & \multicolumn{5}{|c|}{ Potassium } & \multicolumn{5}{|c|}{ Phosphate } & \multicolumn{5}{|c|}{ ONS } \\
\hline Episodes & \multicolumn{5}{|c|}{235} & \multicolumn{5}{|c|}{369} & \multicolumn{5}{|c|}{138} \\
\hline $\begin{array}{l}\text { Number of } \\
\text { times seen }\end{array}$ & $\begin{array}{c}\text { Total } \\
(\mathrm{n})\end{array}$ & 1 & 2 & $>3$ & $\mathrm{MD}$ & $\begin{array}{c}\text { Total } \\
\text { (n) }\end{array}$ & 1 & 2 & $>3$ & MD & $\begin{array}{c}\text { Total } \\
(\mathrm{n})\end{array}$ & 1 & 2 & $>3$ & $M D$ \\
\hline CKD Stage & & & & & & & & & & & & & & & \\
\hline 4 & 124 & 41 & 42 & 24 & 17 & 80 & 24 & 35 & 21 & 0 & 35 & 14 & 4 & 17 & 0 \\
\hline $5 \mathrm{HD}$ & 91 & 17 & 47 & 24 & 3 & 245 & 39 & 104 & 100 & 2 & 79 & 2 & 24 & 49 & 4 \\
\hline 5PD & 5 & 4 & 1 & 0 & 0 & 24 & 4 & 14 & 6 & 0 & 11 & 0 & 1 & 10 & 0 \\
\hline $5 \mathrm{CM}$ & 15 & 5 & 4 & 4 & 2 & 19 & 4 & 11 & 4 & 0 & 10 & 1 & 3 & 6 & 0 \\
\hline MD & 0 & 0 & 0 & 0 & 0 & 1 & 0 & 0 & 1 & 0 & 3 & 0 & 1 & 2 & 0 \\
\hline
\end{tabular}

Table 3 summarises the changes in biochemical and nutritional parameters used to measure aspects of nutritional status during the audit period. Most patients were seen at least twice by the renal dietitian where significant changes were seen in serum potassium and phosphate levels in most CKD stages $(P=0.01)$. For those requiring ONS an increase in weight was noted in haemodialysis patients when seen after three or more consultations $(p=0.01)$.

Significant improvements were seen for both the potassium and phosphate models respectively, as serum potassium levels improved for $87 \%(n=205 / 235)$ and serum phosphate improved for $66 \%$ $(n=245 / 369)$. More than half of the patients referred for ONS $(58 \%, n=81 / 138)$ achieved the outcome. Weight was frequently used as a parameter of nutritional status where $50 \%$ noted weight gain ( $n=62 / 124)$. In some cases, other parameters were used in addition or instead of weight including anthropometry $(n=5), B M I(n=14)$ and SGA $(n=5)$ with all achieving the outcome 
except for albumin where only $38 \%(n=7 / 18)$ achieved the outcome following dietetic

intervention.

Table 3: CKD stage and change in outcome measures for all patients

\begin{tabular}{|c|c|c|c|c|}
\hline CKD Stage & $\begin{array}{l}\text { Episodes of care } \\
\text { (n) }\end{array}$ & Baseline mean (SD) & Final mean (SD) & $P$ value \\
\hline \multicolumn{5}{|c|}{ Potassium management (mmol/l) } \\
\hline CKD Stage 4 & 108 & $5.9(0.33)$ & $5.0(0.38)$ & $<0.01^{*}$ \\
\hline CKD Stage 5 CM & 12 & $5.8(0.28)$ & $5.0(0.5)$ & $<0.01^{*}$ \\
\hline CKD Stage 5 HD & 82 & $6.2(0.89)$ & $5.0(0.61)$ & $<0.01^{*}$ \\
\hline CKD Stage 5 PD & 4 & $5.6(1.7)$ & $4.7(0.75)$ & 0.2 \\
\hline \multicolumn{5}{|c|}{ Phosphate management (mmol/l) } \\
\hline CKD Stage 4 & 50 & $1.83(0.30)$ & $1.42(0.16)$ & $<0.01^{*}$ \\
\hline CKD Stage 5 CM & 6 & $1.77(0.26)$ & $1.49(0.14)$ & $0.03 *$ \\
\hline CKD Stage 5 HD & 162 & $2.03(0.51)$ & $1.44(0.22)$ & $<0.01^{*}$ \\
\hline CKD Stage 5 PD & 17 & $1.93(0.31)$ & $1.42(0.28)$ & $<0.01^{*}$ \\
\hline \multicolumn{5}{|c|}{ Oral nutrition support (weight in kg) } \\
\hline CKD Stage 4 & 17 & $61.7(14.95)$ & $60(14.8)$ & 0.96 \\
\hline CKD Stage 5 CM & 6 & $68.6(17.4)$ & $70.4(16.9)$ & 0.09 \\
\hline CKD Stage 5 HD & 31 & $65.0(15.07)$ & $65.9(14.47)$ & $0.01^{*}$ \\
\hline CKD Stage 5 PD & 6 & $73.2(18.2)$ & $73.7(17.4)$ & 0.46 \\
\hline \multicolumn{5}{|c|}{ Oral nutrition support (BMI in $\mathrm{kg} / \mathrm{m}^{2}$ ) } \\
\hline CKD Stage 4 & 5 & $21.7(4.2)$ & $20.6(4.3)$ & 1.00 \\
\hline CKD Stage 5 CM & 3 & 23.7 (3.9) & $24.3(9.5)$ & 1.00 \\
\hline CKD Stage 5 HD & 2 & $23.5(3.57)$ & $23.5(4)$ & $\mathrm{N} / \mathrm{A}$ \\
\hline CKD Stage 5 PD & 2 & $22.6(2.6)$ & $24.5(3.2)$ & 1.00 \\
\hline
\end{tabular}

Statistical test - Wilcoxon test on difference ${ }^{*} p<0.05$

Table 4: - Goals agreed and whether goal was achieved within the episode of care 


\begin{tabular}{|c|c|c|c|c|c|c|}
\hline \multirow[t]{3}{*}{ Goal } & \multicolumn{6}{|c|}{ Achieved the goal at end of consultation } \\
\hline & \multicolumn{2}{|c|}{ Potassium } & \multicolumn{2}{|c|}{ Phosphate } & \multicolumn{2}{|c|}{ ONS } \\
\hline & A & B & A & $\mathbf{B}$ & $\mathbf{A}$ & $\mathbf{B}$ \\
\hline $\begin{array}{l}\text { Achieve nutritional } \\
\text { adequacy }\end{array}$ & 11 & 2 & 21 & 11 & 32 & 23 \\
\hline Improve oral intake & & & 1 & 2 & 53 & 49 \\
\hline $\begin{array}{l}\text { Improved diet related bowel } \\
\text { function }\end{array}$ & & & 1 & 0 & 3 & 0 \\
\hline Improved functionality & & & & & 1 & 1 \\
\hline $\begin{array}{l}\text { Reduced phosphate related } \\
\text { symptoms }\end{array}$ & 1 & 0 & 19 & 11 & & \\
\hline $\begin{array}{l}\text { Achieve serum potassium } \\
\text { within target range }\end{array}$ & 201 & 30 & & & & \\
\hline $\begin{array}{l}\text { Improve bloods glucose } \\
\text { levels }\end{array}$ & 6 & 0 & 1 & 0 & 1 & 0 \\
\hline $\begin{array}{l}\text { Achieve serum phosphate } \\
\text { within target range }\end{array}$ & 2 & 0 & 241 & 124 & & \\
\hline Achieve target weight & 1 & 0 & 2 & 0 & 5 & 2 \\
\hline Improve BMI & 2 & 1 & 2 & 2 & 11 & 16 \\
\hline Improve anthropometry & & & & & 3 & 1 \\
\hline Reduce fat mass & & & 2 & 2 & 25 & 12 \\
\hline Achieve stable weight & 36 & 6 & 17 & 14 & 28 & 13 \\
\hline $\begin{array}{l}\text { Understand benefits of } \\
\text { dietary advice }\end{array}$ & 130 & 22 & 128 & 68 & 38 & 26 \\
\hline $\begin{array}{l}\text { Understand how to make } \\
\text { dietary changes }\end{array}$ & 90 & 11 & 79 & 44 & 13 & 10 \\
\hline $\begin{array}{l}\text { Achieve agreed dietary } \\
\text { change }\end{array}$ & 36 & 3 & 30 & 11 & 2 & 2 \\
\hline $\begin{array}{l}\text { Able to make agreed changes } \\
\text { to diet }\end{array}$ & 31 & 3 & 11 & 7 & 3 & 1 \\
\hline $\begin{array}{l}\text { Improve motivation to make } \\
\text { changes }\end{array}$ & 4 & 0 & 37 & 21 & 2 & 1 \\
\hline $\begin{array}{l}\text { Improve concordance with } \\
\text { relevant prescribed products }\end{array}$ & 60 & 15 & 97 & 49 & 37 & 26 \\
\hline $\begin{array}{l}\text { Patient has positive } \\
\text { experience }\end{array}$ & 53 & 4 & 89 & 37 & 9 & 13 \\
\hline
\end{tabular}

$A=$ Achieved overall outcome. $B=$ did not achieve overall outcome 


\section{Goals}

Goals were agreed at the start of the consultation as shown in table 4. The majority of goals linked to biochemistry, nutritional status, motivation and knowledge. For those who did not achieve the overall desired outcome (B), 50\% ( $n=181 / 362)$ of the patients still demonstrated an improvement in knowledge and $50 \%(n=33 / 66)$ in motivation and importance of dietary advice.

\section{Barriers}

To add context to the data, the dietitian identified barriers present at the start and end of the episode of care. The \% change in each barrier is shown in table 5 where "no barriers" consistently increased by the end of the episode of care for each model.

\section{$\underline{\text { Intervention }}$}

The dietitians recorded how they may have overcome some of these barriers using various 'interventions'. Where interventions such as 'provide individualised information in a suitable format' and 'provide further advice to improve knowledge' were utilised, a positive impact on patients outcomes were observed. "Non dietetic interventions" were also noted such as patient receiving a transplant ( $n=5 / 742)$, starting dialysis $(n=36 / 742)$, having dialysis dose increased ( $n=10 / 742$ ) or other medical/surgical procedures ( $n=9 / 742)$, all achieving a positive outcome. Where interventions requiring liaising with medical or nursing staff were utilised this negatively affected the patient's outcome. In these cases delays in acquiring medication were identified as a barrier. 
Table 5: \% change in the number of barriers identified by the renal dietitian from the beginning and end of the episode of care.

\begin{tabular}{|c|c|c|c|c|}
\hline \multirow{2}{*}{\multicolumn{2}{|c|}{ Barrier }} & \multicolumn{3}{|c|}{ Change (\%) } \\
\hline & & Potassium & Phosphate & ONS \\
\hline 0 & No barriers & +82 & +83 & +119 \\
\hline \multirow{4}{*}{$\begin{array}{l}1 \\
\text { Behavioural }\end{array}$} & Low motivation & -48 & -34 & +17 \\
\hline & Low confidence to change & -100 & -81 & -75 \\
\hline & $\begin{array}{l}\text { Poor adherence with } \\
\text { medications/supplements }\end{array}$ & -16 & -85 & +33 \\
\hline & Poor attendance & 0 & +700 & 0 \\
\hline \multirow{2}{*}{$\begin{array}{l}2 \\
\text { Psychological }\end{array}$} & Low mood/anxiety & -44 & -42 & -18 \\
\hline & Disordered eating & -50 & -29 & -56 \\
\hline \multirow{5}{*}{$\begin{array}{l}3 \\
\text { Practical/social }\end{array}$} & Poor/lack of cooking facilities & -100 & -33 & -67 \\
\hline & Impaired ability to shop & -41 & -46 & -50 \\
\hline & Financial difficulties & & +100 & +100 \\
\hline & Lack of social support & +100 & -40 & -67 \\
\hline & Lifestyle issues & -66 & -47 & 0 \\
\hline \multirow{5}{*}{$\begin{array}{l}4 \\
\text { physical/symptom }\end{array}$} & Anorexia & -50 & -14 & -60 \\
\hline & Gl symptoms & -38 & -31 & -64 \\
\hline & Dysphagia & & -100 & -100 \\
\hline & Fatigue & -100 & -80 & -60 \\
\hline & Pain & & -50 & -25 \\
\hline \multirow[t]{5}{*}{$\begin{array}{l}5 \\
\text { information }\end{array}$} & $\begin{array}{l}\text { Unsuitable sources of additional } \\
\text { information e.g. internet }\end{array}$ & -100 & -100 & \\
\hline & Poor understanding & -61 & -72 & -57 \\
\hline & Literacy/ language barriers & 0 & -33 & 0 \\
\hline & $\begin{array}{l}\text { Learning difficulties/cognitive } \\
\text { impairment }\end{array}$ & -11 & -21 & 0 \\
\hline & Lack of capacity & +100 & 0 & \\
\hline \multirow{5}{*}{$\begin{array}{l}6 \\
\text { Organisational }\end{array}$} & Problems with meal provisions & -86 & -100 & +100 \\
\hline & Poor/inadequate staffing & 0 & -6 & +12 \\
\hline & $\begin{array}{l}\text { Delay in acquiring } \\
\text { medication/supplements }\end{array}$ & & -43 & -100 \\
\hline & Delay in starting dialysis & -100 & +100 & -200 \\
\hline & Poor access to clinic/support groups & & & \\
\hline \multirow{8}{*}{$\begin{array}{l}7 \\
\text { Medical }\end{array}$} & Co-morbidity - pt has CVD & +33 & +100 & -25 \\
\hline & Co-morbidity - pt has diabetes & -21 & -13 & -75 \\
\hline & $\begin{array}{l}\text { Adverse changes in medical } \\
\text { conditions }\end{array}$ & -75 & +80 & +38 \\
\hline & Inadequate dialysis & -72 & -44 & -400 \\
\hline & Modality change (HD-PD) & -50 & -67 & \\
\hline & Patient not for dialysis & -100 & -50 & 0 \\
\hline & Frequent hospital admissions & +100 & 0 & -25 \\
\hline & $\begin{array}{l}\text { Clinical decision not to prioritise } \\
\text { dietetic intervention }\end{array}$ & & +300 & 0 \\
\hline \multirow[t]{2}{*}{$\begin{array}{l}8 \\
\text { Pharmacology }\end{array}$} & $\begin{array}{l}\text { Delay in acquiring } \\
\text { medication/supplements }\end{array}$ & -100 & -27 & -60 \\
\hline & $\begin{array}{l}\text { Medication change adversely } \\
\text { affecting dietetic outcome }\end{array}$ & -71 & -33 & -75 \\
\hline
\end{tabular}




\begin{tabular}{|l|l|l|l|l|}
\hline $\mathbf{9}$ & Biochemical & -100 & -62 & -100 \\
\cline { 2 - 5 } & PTH above or below RA guidelines & & -27 & \\
\cline { 2 - 5 } & Low bicarbonate levels & -75 & -100 & -100 \\
\hline $\begin{array}{l}\mathbf{1 0} \\
\text { Other }\end{array}$ & Other & -47 & -29 & -50 \\
\hline
\end{tabular}

-= reduction, +=increase

\section{Discussion}

The aim of this multicentre audit was to determine if the use of the RDOT could capture changes in parameters used to measure nutritional status and biochemical measures in patients with CKD receiving dietetic intervention in clinical practice.

$87 \%$ of patients were able to show a clinically significant improvement in their biochemical levels for potassium and $66 \%$ for phosphate management, whilst under the care of the renal dietitian. Improvements in phosphate management have been observed previously with dietetic intervention (Sullivan et al. 2009; Reddy et al. 2009; Caldeira et al. 2011; Karavetian and Ghaddar 2013). For the ONS model, just over half of the patients were able to show a small increase in body weight though this change was not significant except in haemodialysis patients. This may have been due to several factors including: weight maintenance being a more appropriate goal than weight gain; an insufficient length of time for follow up to see a clinically significant change (mean length of episode of care for ONS was 101 days); weight being affected by fluid status or the presence of several non-modifiable barriers e.g. frequent hospital admissions (which were frequently found in this patient group). Albumin was also used as a measure of nutritional status in this audit, however the reliability of this parameter is questioned due to the influence of nonnutritional factors (Friedman and Fadem, 2010)

The RDOT not only captured the outcome of the patients during the audit period but provided context to the results recorded. Goals agreed with the patient at the start of the episode of care 
demonstrated the steps used to help achieve overall outcome e.g. increase knowledge or reduce symptoms. This was particularly beneficial in instances where the outcome was not achieved e.g. phosphate may not be in target range at the end of dietetic intervention but individual goals may have been achieved such as reduce phosphate related symptoms, understand benefits of dietary advice or where the outcome may not have been solely influenced by dietetic care e.g. when a patient receives improvement in dialysis treatment.

Healthcare professionals can make assumptions regarding their impact without appreciating the context of external influences in clinical practice. Recording the presence of a barrier appeared to predispose whether patients achieved their outcome for all three outcome models. Therefore it would appear essential to record these at the start of any dietetic intervention and implement strategies to overcome them. In fact, the results illustrated that through dietetic intervention, many patients were able to reduce their number of modifiable barriers.

Some interventions influenced the achievement of outcomes. Yet it was of particular interest that patients were less likely to achieve their outcome for phosphate management if the intervention 'Identify problems and liaise with medical/nursing staff' was reported. Whilst it cannot be certain what problems were identified in each case, it is quite likely that issues around binder prescription were amongst these. This is further supported by the identified barrier 'delays in acquiring medication' being an additional barrier to achieving outcome in phosphate management. Therefore the recent legislation change which allows dietitians to supplementary prescribe is most welcomed. In some units, the use of established local protocols and patient group directions may at least go some way to overcome this issue.

One limitation of this audit is that it has relied on the accuracy of the individual dietitians when completing the RDOT. To minimise this effect an audio visual guide, a Frequently Asked Questions' document and a mentor from the Working Group was provided. Despite this, Inter-person 
variability will undoubtedly have taken place, as often patients are seen by more than one renal dietitian within any unit. It was also noted that some of the entries were incomplete indicating that the practice of collecting outcomes is still not embedded in clinical practice. An evaluation questionnaire was used to obtain feedback from the participants. The results were collated as seen via this link https://www.bda.uk.com/regionsgroups/groups/renal/evaluation of outcomes tool. In order to overcome some of these limitations in future use, a 'How to Guide' has been developed for use alongside the RDOT and is available on the Think Kidneys website.

This multi centre audit has shown that renal dietetic interventions are effective for patients with late stages of CKD. The RDOT provides the ability to visualise changes in clinical parameters whilst capturing important data relating to a patients' outcome. This is vital to renal dietitians and commissioners of services in the current NHS climate. And whilst this is only a starting point for collecting data it has been used to influence other specialist dietetic groups regarding capturing outcomes in practice - particularly detailing barriers which may limit outcomes. This will help to shape services, question historic practice and aid health care professionals to prove their worth. 


\section{$\underline{\text { References }}$}

Ash S, Campbell KL, Bogard J, Millichamp A. 2014. Nutrition prescription to achieve positive outcomes in Chronic Kidney Disease: A systematic review. Nutr. 6: 416-51

Bellizzi V, Di lorio BR, Brunori G, De Nicola L, Minutolo R, Conte G, et al. 2010. Assessment of nutritional practice in Italian chronic kidney disease clinics: a questionnaire-based survey. J. Ren. Nutr. $20(2): 82-90$

BDA (British Dietetic Association). 2011. Model for Dietetic Outcomes [Internet]. [cited 2016 Nov 1]. Available from:

https://www.bda.uk.com/publications/archive/bda_outcome_model_2011_archive

BDA (British Dietetic Association). 2016. Model and Process for Nutrition and Dietetic Practice. [Internet]. [cited 2017 Oct 1]. Available from:

https://www.bda.uk.com/professional/practice/process

Caldeira D, Amaral T, David C, Sampaio C. 2011. Educational strategies to reduce serum phosphorus in hyperphosphatemic patients with chronic kidney disease: systematic review with meta-analysis. J. Ren. Nutr. 21(4):285-94

Campbell KL, Ash S, Zabel R, McFarlane C, Juffs P, Bauer JD. 2009. Implementation of Standardized Nutrition Guidelines by Renal Dietitians Is Associated With Improved Nutrition Status. J. Ren. Nutr. 19(2):136-44

Davies J on behalf of the BDA (British Dietetic Association) Oncology Specialist Group. 2016. 
Outcomes tool guidance. [Internet]. [cited Feb 8] Available from:

https://www.bda.uk.com/regionsgroups/groups/oncology/resources

DOH (Department of Health). 2010. Equity and excellence: Liberating the NHS [Internet]. [cited 2016 Nov 1]. Available from:

https://www.gov.uk/government/uploads/system/uploads/attachment data/file/213823/dh 117

794.pdf

DOH (Department of Health). 2016. NHS outcomes Framework: at-a-glance [Internet]. [cited 2018 Feb 8]. Available from:

https://assets.publishing.service.gov.uk/government/uploads/system/uploads/attachment_data/f ile/513157/NHSOF at a glance.pdf

Enderby P, John A. 2015. Therapy outcome measures for rehabilitation professionals 3rd edition. Guilford: J7R Press.

Friedman AN, Fadem SZ. 2010. Reassessment of Albumin as a nutritional marker in kidney disease. JASN [Internet]. 21(2):223-230. [cited 2018 August 3] Available from:

http://jasn.asnjournals.org/content/21/2/223.full

Gardiner C, Harman A, Alderdice J. 2015. The renal group outcome tool, how it was developed clinical nutrition. Complete Nutrition. 15(3):63-66

HCPC (Health and Care Professions Council). 2013. Standards of Proficiency - Dietitians. [Internet]. [cited 2016 Nov 1]. Available from: http://www.hpc- 
uk.org/assets/documents/1000050CStandards of Proficiency Dietitians.pdf

Karavetian M, Ghaddar S. 2013. Nutritional education for the management of osteodystrophy (NEMO) in patients on haemodialysis: A randomised controlled trial. J. Ren. Care. 39(1):19-30

Malcomess K, Wilson J. 2015. Care aims, well-being outcomes collaborative. [Internet]. [cited 2018 Feb 8]. Available from: http://careaims.com/

NHS England. 2014. FIVE YEAR FORWARD VIEW. [Internet]. [cited 2016 Nov 1]. Available from: https://www.england.nhs.uk/wp-content/uploads/2014/10/5yfv-web.pdf

PENG (Parenteral and Enteral Nutrition Group). 2016. The Dietetic Outcomes Toolkit. [Internet]. Available from: http://www.peng.org.uk/pdfs/publications/peng-dietetic-outcomes-toolkit.pdf Reddy V, Symes F, Sethi N, Scally AJ, Scott J, Mumtaz R, et al. 2009. Dietitian-Led Education Program to Improve Phosphate Control in a Single-Center Hemodialysis Population. J. Ren. Nutr. 19(4):314-20

Steiber AL, León JB, Hand RK, Murphy WJ, Fouque D, Parrott JS, et al. 2015. Using a Web-Based Nutrition Algorithm in Hemodialysis Patients. J. Ren. Nutr. 25(1):6-16

Stratton RJ, Bircher G, Fouque D, Stenvinkel P, de Mutsert R, et al. 2005. Multinutrient oral supplements and tube feeding in maintenance dialysis: a systematic review and meta-analysis. Am. J. kidney dis. 46(3):387-405 
Sullivan C, Sayre SS, Leon JB, Machekano R, Love TE, Porter D, et al. 2009. Effect of food additives on hyperphosphatemia among patients with end-stage renal disease: a randomized controlled trial. JAMA [Internet]. 301(6):629-35. Available from:

http://www.ncbi.nlm.nih.gov/pubmed/19211470

R Core Team. 2015. R: A language and environment for statistical computing. R Foundation for Statistical Computing, Vienna, Austria. URL https://www.R-project.org/. 


\section{Key Points}

1. Providing both cost effective and clinically effective services is essential in today's NHS. However, it can be difficult to capture this data in day to day practice.

2. The identification and development of outcome measures for dietetics has been an ongoing challenge for the profession.

3. This article describes how the Renal Nutrition Group of the British Dietetic Association developed three renal-specific Dietetic Outcome Models and a Renal Dietetic Outcome Tool (RDOT) to measure dietetic outcomes in potassium and phosphate management and oral nutrition support in patients with Chronic Kidney Disease (CKD) for use in daily clinical practice.

4. The results from the audit showed that renal dietetic interventions are effective for patients with late stages of CKD.

5. The outcomes tool was found to be a useful addition to clinical practice as it records changes in clinical parameters whilst capturing details of the dietetic intervention and other relevant factors, including barriers.

6. The tool could be modified to incorporate other dietetic models (such as fluid management or weight management), goals, barriers and dietetic interventions for other specialist areas. These aspects are vital to dietitians and commissioners of services in the current NHS climate. 


\section{Reflective Questions}

1. What are the main challenges in demonstrating that dietitians are both cost and clinically effective in todays NHS?

2. What are the limitations in the current research into the effectiveness of Renal dietitians?

3. What were the primary and secondary aims of this audit? Did it meet its aims?

4. Which dietetic intervention was found to be the most effective - and which the least?

Why do you think this was?

5. What findings were of specific interest to Renal dietitians and what do you think can be generalisable to other clinical areas within Dietetics? 